\title{
First light microscopy and ultrastructural description of Mesocoelium sociale (Luhe, 1901) Odhner, 1910 (Trematoda: Mesocoeliidae) in Bufo regularis from Egypt
}

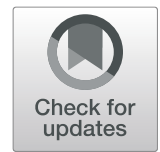

Hasnaa Thabit ${ }^{*}$ and Refaat Khalifa ${ }^{2}$

\begin{abstract}
Background: Mesocoeliidae is a common parasite of the small intestine of amphibians and reptiles. From Egypt, only Mesocoelium monas (Rudolphi C., Berolini 811 (1819)) (Freitas JF, Revista Brasiliera de Biologia 18:171-174, (1958)) was reported and described by (Saad Al et. al., J Egypt Ger Soc Zool 33: 219-234, (2000)) from the small intestine of the Egyptian toads Bufo regularis from Aswan Governorate, Upper Egypt, and the molecular characterization of the same parasite was reported by (Mansour MFA et. al., Egypt. J. Biol. (Zool.),10:(1)1-8, (2014)) without any morphological description from the same final host. The present study aimed to detect the prevalence and the characteristic morphological features of mesocoeliid parasites of the Egyptian toads Bufo regularis.

Methods: Toads were collected from Assiut and Giza Governorates during the autumn of 2018. They were dissected and examined by a dissecting microscope for intestinal parasites. The collected trematodes were fixed, stained, dehydrated, cleared, and mounted. Photomicrographs were taken and parasite measurements were determined. Some of the identified worms were prepared for scanning electron microscope for studying their ultrastructure.

Results: Mesocoelium sociale was detected from the small intestine of 14 out of 51 toads Bufo regularis (27.5\%) with worm burden (10-30 worms per host). Detailed morphometric characteristic features of the parasite were described by a light microscope. Scanning electron microscopy showed many fine ultrastructure details in the present study and confirmed the light microscopic description.

Conclusion: Mesocoelium sociale (Luhe M, Centralblatt für Bakteriologie Parasitenkunde und Infektionsk-rankheiten, 30, 166-177, (1901)) (Odhner T., Res. Swedish Zool Exped Egypt iv, (23a), 1-166, (1910)) is recorded for the first time from Egypt as a trematode parasite of the Egyptian toads' Bufo regularis and described by a light microscope. In addition, it is described for the first time worldwide by scanning electron microscopy.
\end{abstract}

Keywords: Egyptian toad, Bufo regularis, Mesocoelium sociale, SEM, Taxonomy

\footnotetext{
* Correspondence: hasnaa.thabet@science.aun.edu.eg

'Laboratory of Parasitology, Department of Zoology, Faculty of Science,

Assiut University, Assiut 71526, Egypt

Full list of author information is available at the end of the article
}

\section{Springer Open}

( ) The Author(s). 2020 Open Access This article is licensed under a Creative Commons Attribution 4.0 International License, which permits use, sharing, adaptation, distribution and reproduction in any medium or format, as long as you give appropriate credit to the original author(s) and the source, provide a link to the Creative Commons licence, and indicate if changes were made. The images or other third party material in this article are included in the article's Creative Commons licence, unless indicated otherwise in a credit line to the material. If material is not included in the article's Creative Commons licence and your intended use is not permitted by statutory regulation or exceeds the permitted use, you will need to obtain permission directly from the copyright holder. To view a copy of this licence, visit http://creativecommons.org/licenses/by/4.0/. 


\section{Background}

Identified species of the genus Mesocoelium (Trematoda: Mesocoeliidae) are small intestinal parasites of amphibians (mainly frogs and toads) and reptiles all over the world (Skrjabin \& Morozov, 1959; Cheng, 1960; Freitas, 1963) and only one species from fish was reported and described from a single specimen from Malaysia (Fiscthal \& Kuntz, 1965). From Egypt, only Mesocoelium monas (Rudolphi, 1819) Freitas, 1958 was reported and described by Saad et al. (2000) from the small intestine of the Egyptian toads' Bufo regularis from Aswan Governorate, Upper Egypt, and its molecular characterizations were described by Mansour et al. (2014) from toads collected from El-Mansoura city (Dakahliya Governorate) and Abo Rawash region (Giza Governorate), Lower Egypt. The taxonomy of the genus Mesocoelium is complex and has been the subject of considerable controversy (Gomes et al., 2013). Moreover, from established species previously described, the SEM ultrastructure of only one species $M$. lanfrediae was reported by Gomes et al. (2013). Calhoun and Dronen (2012) considered the taxonomic and specific characters chosen for their specific diagnosis to be unreliable and controversial and emphasized the need for additional study to evaluate these species. The present study aimed to detect the prevalence and the characteristic morphological features of mesocoeliid parasites of the Egyptian toads' Bufo regularis.

\section{Materials and methods \\ Collection of toads}

Fifty-one samples of Egyptian toads Bufo regularis are obtained from Assiut Governorate and Abo-Rawash region (Giza Governorate), Egypt, during the autumn of 2018. They were brought to the Laboratory of Parasitology, Zoology Department, Faculty of Science, Assiut University, Egypt. They were dissected; the alimentary canal was removed, opened in petri-dish containing $0.9 \%$ sterile saline solution, and examined by dissecting microscope for intestinal parasites.

\section{Preparation of parasites for light microscopy}

The collected trematode worms were washed several times by saline solution to be freed from the mucous or any other debris and left for $1 \mathrm{~h}$ in the refrigerator for relaxation before flattening between two slides or between a slide and a thin glass coverslip according to the size of the worms. Then, they were fixed in neutral buffered $10 \%$ formalin and kept in $70 \%$ ethyl alcohol. The worms were stained with acetic acid-alum carmine, dehydrated in ascending grades of ethanol $(70 \%, 80 \%, 90 \%, 95 \%$, and $100 \%$ ), cleared in xylene, mounted in DPX, and covered with a thin coverslip. Photomicrographs were taken using a digital camera. Identification of worms was done using the standard key of (Yamaguti, 1958). All measurements are in microns unless otherwise mentioned and shown as the range, followed by the mean \pm S.E. in parentheses.

\section{Preparation of parasites for scanning electron microscopy} Some of the identified worms were washed several times in normal saline solution and fixed in 5\% cold glutaraldehyde for $24 \mathrm{~h}$. Specimens were washed three times in phosphate buffer and post-fixed in 1\% osmium tetroxide for $2 \mathrm{~h}$ and then washed three or four times in the same buffer. Specimens were dehydrated in ascending grades of ethanol, dried, mounted on the special holders, and coated with gold. The worms were viewed with a JEOL JSM-5400LV SEM operated at $15 \mathrm{kV}$ in the electron microscopy unit, Assiut University.

\section{Results}

Taxonomic summary

Phylum Platyhelminthes

Class Trematoda

Subclass Digenea

Family Mesocoeliidae Dollfus, 1929

Genus Mesocoelium Odhner, 1910

Species Mesocoelium sociale (Luhe, 1901) Odhner, 1910

Host: Bufo regularis.

Locality: Assiut and Giza Governorates, Egypt.

Site of infection: Small intestine.

Prevalence: $27.5 \%$ (14/ 51).

Intensity of infection: 10-30 worms per infected toad.

Material deposited in: Zoology Department, Faculty of Science, Assiut University.

\section{Description (Figs. 1, 2, 3, 4, 5)}

This is based on 11 mature specimens; morphometric data is shown in Table 1. The living worms were creamy to brownish in color with different body shapes (Figs. 1a, $\mathrm{b}$ and $2 \mathrm{a}$ ), whereas their bodies appear to be elongated, fusiform, spoon-shaped, linguiform, or oval-shaped. They had highly flexible bodies where the anterior extremity of the worm could be extended two or three times the original length of their bodies. The length of the body varied between 776.7 and $2807.9 \mu \mathrm{m}$ (2039.98 $\pm 219.88 \mu \mathrm{m})$. The body width varied greatly at different body levels. The greatest width ranged between 434.2 and $897.5 \mu \mathrm{m}(730.51 \pm 45.6 \mu \mathrm{m})$. The anterior part from oral to ventral suckers slightly curved ventrally. The entire body surface is wrinkled and covered with spines (Fig. 5a). The tegumental spines are denser in the middle third of the body and decrease at the anterior and posterior ends of the body ((Figs. 4b and 5c). They are numerous around ventral sucker (Fig. 4d) becoming progressively sparse in distribution to become very sparse in the posterior part of the body which is translucent showing the uterine coils filled with eggs (Fig. 5c). High magnification showed that tegument is provided with curved distal-end spines arranged in 

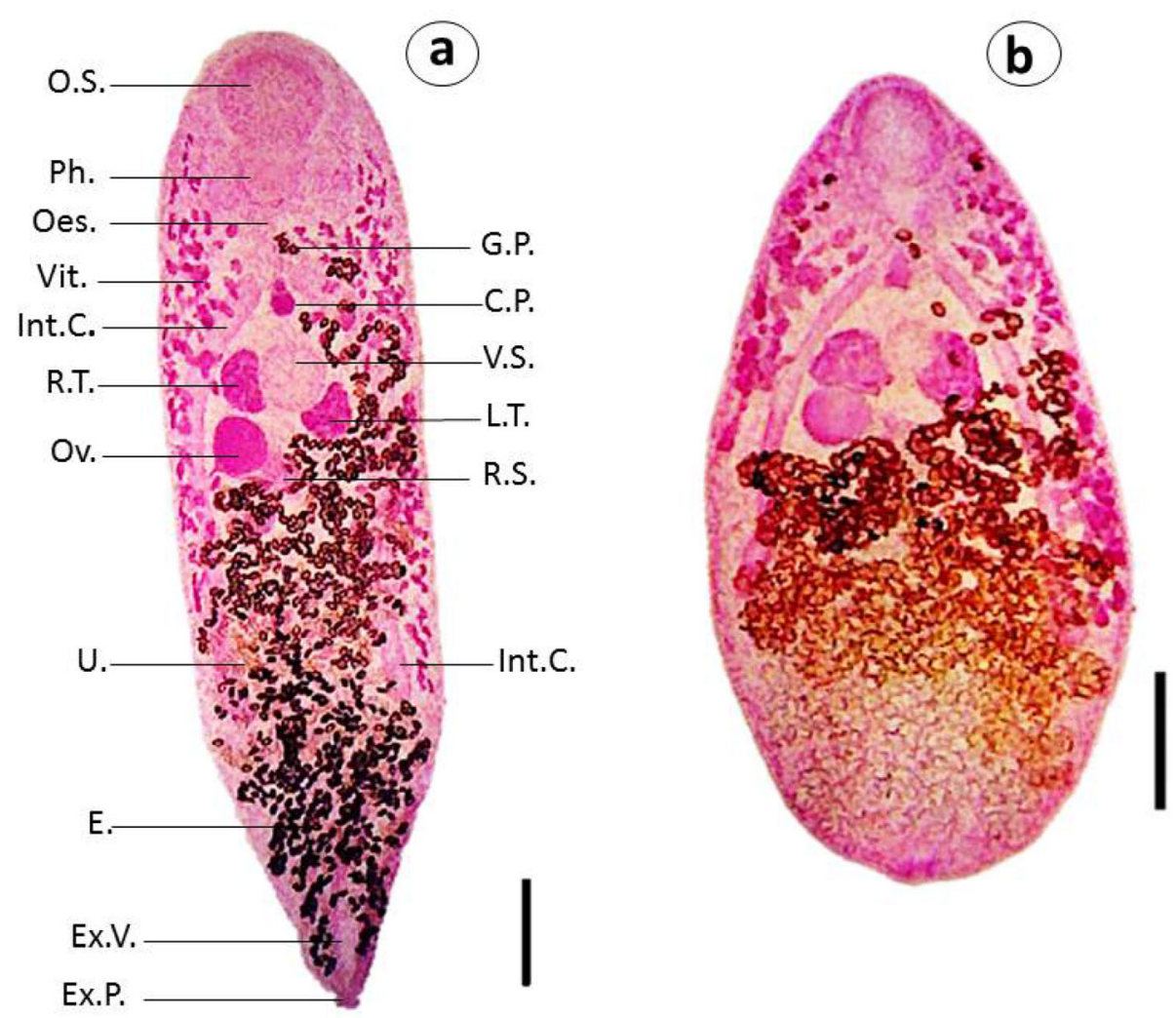

Fig. 1 a, b Photomicrographs of Mesocoelium sociale showing variations in the body shape of the adult worms. Abbreviations: C.P., cirrus pouch; E., egg; Ex.P., excretory pore; Ex.V., excretory vesicle; G.P., genital pore; Int.C., intestinal caecum; L.T., left testis; Oes., esophagus; O.S., oral sucker; Ov., ovary; Ph., pharynx; R.S., receptaculum seminis; R.T., right testis; U., uterus; Vit., vitellaria; V.S., ventral sucker. Scale bars, a, b $=300 \mu m$

transverse rows (Fig. 5b). The oral sucker is muscular, rounded or oval in shape, and subterminal in position (Fig. 3a, b). It surrounds the mouth opening that appears as a vertical slit (Fig. 4b) or a wide deep hole (Fig. 4c). It measures $115.6-283.6 \mu \mathrm{m}(214.82 \pm 16.48 \mu \mathrm{m})$ in length by $138.3-312.3 \mu \mathrm{m}(221.63 \pm 15.72 \mu \mathrm{m})$ in width. It was followed by the muscular pharynx measuring 62.3$172.2 \mu \mathrm{m}(119.24 \pm 10.78 \mu \mathrm{m})$ in length by $68.5-224.8 \mu \mathrm{m}$ $(141.92 \pm 15.14 \mu \mathrm{m})$ in width. The relatively short esophagus measured $16.8-163.7 \mu \mathrm{m}(72.41 \pm 14.93 \mu \mathrm{m})$ in length bifurcates immediately into two tubular simple intestinal caeca that reach to the beginning of the last fourth of the body. The ventral sucker is smaller than the oral one and rounded in shape (Fig. 3a). It appears to be sessile (Fig. 4b) or on a very short peduncle (Fig. 4c). It measures 81.5$192.5 \mu \mathrm{m}(140.71 \pm 11.23 \mu \mathrm{m})$ long by $84.3-187.4 \mu \mathrm{m}$ $(132.67 \pm 10.3 \mu \mathrm{m})$ wide. The distance between the two suckers is $132.4-674.4 \mu \mathrm{m}(379.3 \pm 50.2 \mu \mathrm{m})$. The two testes are very variable in shape and size, kidney-shaped, ovoid, spherical, irregular or half-moon in shape, partially surpassed by the sides of the acetabulum. In all samples, they were located very near or in a touch of each side of the ventral sucker and obliquely tandem in position (Fig. 3a, c). The left testis measures 66-220.3 $\mu \mathrm{m}$ (154.6 $\pm 15.6 \mu \mathrm{m})$ in length by $58.8-218.6 \mu \mathrm{m}(133.19 \pm$ $15.91 \mu \mathrm{m})$ in width and the right one measures 59.2$221.2 \mu \mathrm{m}(140.5 \pm 14 \mu \mathrm{m})$ length by $59.4-179.1 \mu \mathrm{m}$ $(122.75 \pm 12.68 \mu \mathrm{m})$ in width. Cirrus pouch is in the form of the small pyriform sac with a tapering necklike canal ending in the genital pore, besides the uterine pore. The ovary is spherical or oval-shaped and lies under the right testis, usually separated from it by a very narrow space (Figs. 1a, 2a, and 3a, c), rarely in touch with it (Fig. 1b). It measures 41.5-191 $\mu \mathrm{m}$ $(122.53 \pm 14.93 \mu \mathrm{m})$ by $70.5-164.2 \mu \mathrm{m} \quad(127.92 \pm$ $10 \mu \mathrm{m})$. Receptaculum seminis is located posterolateral to the ovary, characterized by being very variable in size and shape (Fig. 3a, c). The vitellaria are in the form of separated medium-sized follicles filling the lateral sides of the body extending from oral sucker or pharynx till the end of intestinal caeca; usually, not confluent intercaecally but few follicles rarely were seen intercaecally; usually bilaterally symmetrical in distribution (Figs. 1a and 2a), but rarely asymmetrical (Fig. 1b). The genital pore is situated prebifurcal and submedian in all samples (Fig. 2a). The uterus fills most of the body containing a large number of eggs and opens in the common genital pore. The excretory pore is located at the posterior 

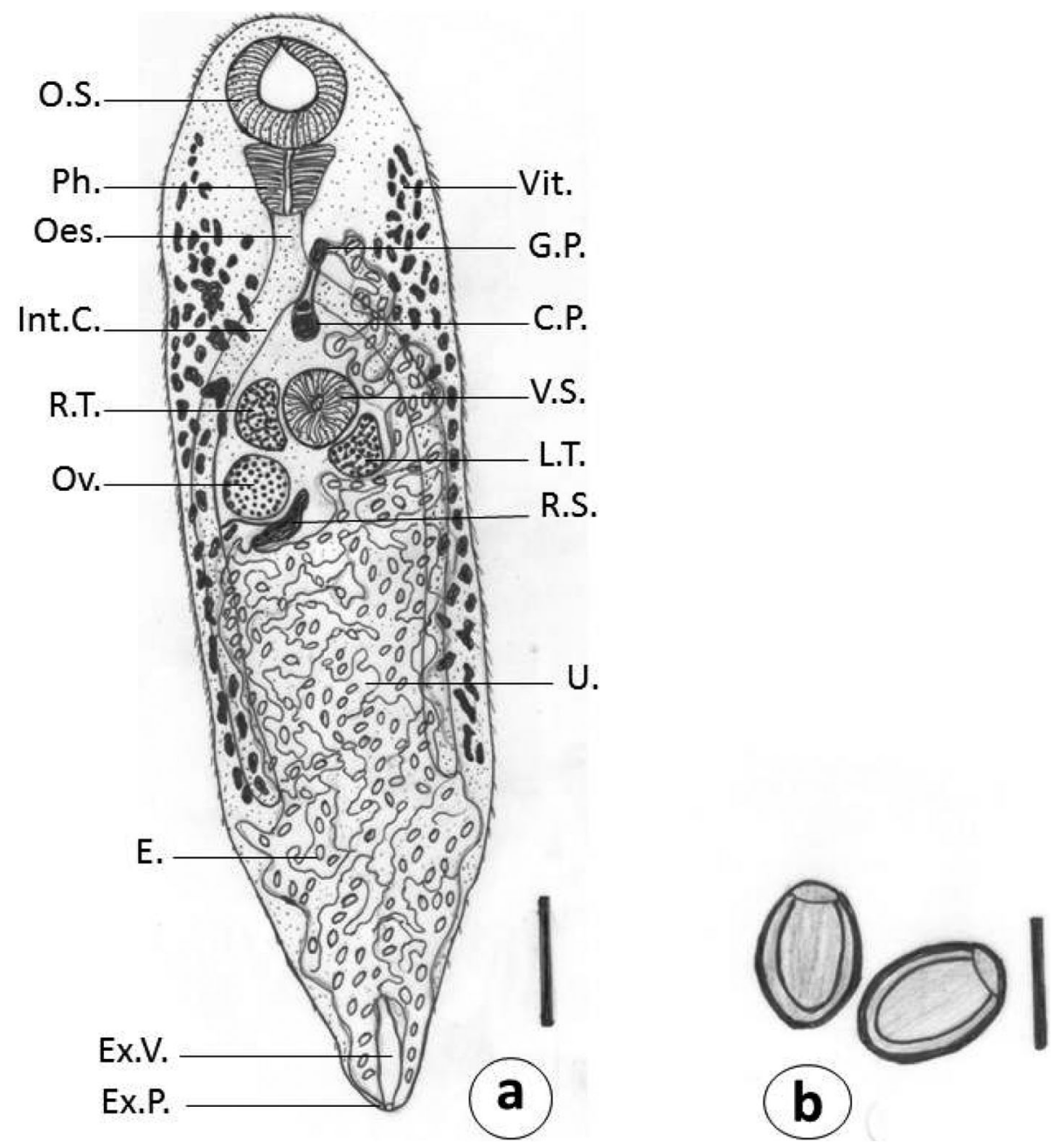

Fig. 2 Line diagram of Mesocoelium sociale. a Shows ventral view of whole worm. Abbreviations: C.P., cirrus pouch; E., egg; Ex.P., excretory pore; Ex.V., excretory vesicle; G.P., genital pore; Int.C., intestinal caecum; L.T., left testis; Oes., esophagus; O.S., oral sucker; Ov., ovary; Ph., pharynx; R.S., receptaculum seminis; R.T., right testis; U., uterus; Vit., vitellaria; V.S., ventral sucker. Scale bar $=300 \mu \mathrm{m}$. b Shows the eggs. Scale bar $=30 \mu \mathrm{m}$

extremity of the worm (Figs. 1a, 2a, and 5c). The excretory vesicle is sac-shaped. The eggs are yellowish or brown in color, oval-shaped, and operculated with thick convex shells (Figs. 2b, 3d, and 5d). It measures $32.8-35.6 \mu \mathrm{m}$ $(34.1 \pm 0.27 \mu \mathrm{m})$ by $19.7-24.5(22.52 \pm 0.52 \mu \mathrm{m})$.

\section{Discussion}

Goldberg, Bursey, and Telford Jr. (2005) stated that Mesocoelium is represented as suspected only by a single species, M. monas, while Calhoun and Dronen (2012) reevaluated the specimens of $M$. monas from the National History $\mathrm{Mu}-$ seum, UK, and the US National Parasite Collection, USA, and concluded that the result of their study suggested that $M$. monas is not as cosmopolitan as previously thought and has a much narrow distribution worldwide than is currently suggested and called for carrying out a comparative study using both molecular and morphological techniques to confirm morphological species identification and to clarify the existing confusion in this species.

According to the family and genus, diagnostic features presented by Yamaguti (1971) and recently, the keys presented by Dronen, Calhoun, and Simcik (2012), the present specimens belong to the family Mesocoeliidae Dollfus, 1929 and genus Mesocoelium Odhner, 1910 and identified as Mesocoelium sociale (Luhe, 1901) Odhner, 1910 which was considered as the type of species of the genus. M. sociale was separated from all other species by having moderately long caeca surpassing the ovary posteriorly, submedian prebifurcal genital pore, and posterior extent of the vitelline follicles alongside the caeca. The parasite was first described by Luhe (1901) as Distomum sociale from toads originally collected from Burma (now Myanmar). Freitas (1963) considered M. sociale to be synonymous with $M$. monas (Rudolphi, 1819) while Skrjabin and Morozov (1959) and Wongsawad et al. (1998) 


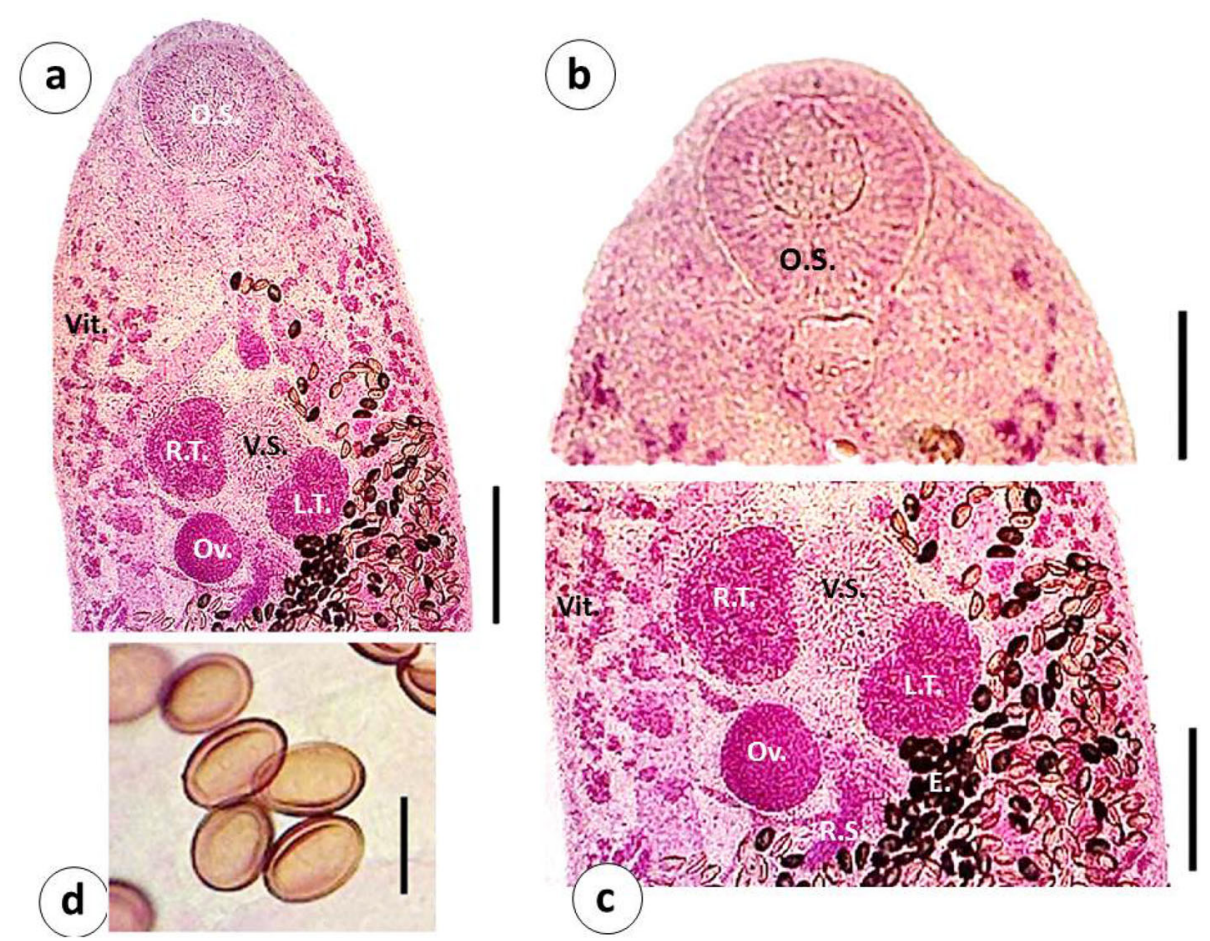

Fig. 3 Photomicrographs of Mesocoelium sociale. a magnified anterior worm body Shows left testis (L.T.), oral sucker (O.S.), ovary (Ov.), right testis (R.T.), vitellaria (Vit.), ventral sucker (V.S.). Scale bar $=300 \mu \mathrm{m}$. b Shows magnified oral sucker (O.S.). Scale bar $=200 \mu \mathrm{m}$. c Shows details of eggs (E.), left testis (L.T.), ovary (Ov.), receptaculum seminis (R.T.), right testis (R.T.), vitellaria (Vit.), and ventral sucker (V.S.). Scale bar $=200 \mu m$. d Shows the eggs. Scale bar $=30 \mu \mathrm{m}$

regarded it as a valid species. $M$. sociale is a parasite of the intestines of amphibians and reptiles exhibiting limited host specificity. It was mainly identified from toads, but Norval, Goldberg, Bursey, Mao, and Slater (2014) identified it from five different species of lizards and only once from a fish (Fiscthal \& Kuntz, 1965).

M. sociale was redescribed by Cheng (1960) from India, Wongsawad et al. (1998) from Thailand, Dronen et al. (2012) from Malaysia and Ray, Agrawal, and Pandey (2017) from India from the amphibians Bufo melanostictus, Kaloula pulchra, Bufo asper, and Duttaphrynus melanostictus, respectively. Comparing the present specimen from the previously described forms (Table 1) leads to the following remarks:

1- Body shape: It was elongate in all previously redescribed forms while in the present samples, it was very variable (elongate, fusiform, lingiuform, pear-shaped, oval, or spoon-shaped). It seems that the shape of the body depends mainly on the state of contraction or relaxation at the time of fixation of the worms.

2- Body length: Generally, it is very variable as the range between the smallest and biggest samples. Regardless of the body size, all specimens were mature with uteri fully engorged with eggs. Moreover, samples of Ray et al. (2017) were exceptionally very small (less than $1 \mathrm{~mm}$ ) which may be due to the low number of described specimens.

3- Body width: All redescribed forms were more or less of the same range except those of Ray et al. (2017) which were exceptionally narrow (less than $1 / 3$ the width of all forms).

4- Size of suckers: Regarding oral sucker, more or less the length and width of all samples were within the same range except for that described by Ray et al. (2017) in which the oral sucker was about twice bigger despite being in smaller bodies..

5- Prepharynx length: This was not reported before, although it was mentioned as the present (Cheng, 1960) and short (Wongsawad et al., 1998; Dronen et al., 2012), while it was not observed in the present samples and those of Ray et al. (2017).

6- Pharynx length: This was slightly shorter in Dronen et al. (2012) and larger in Ray et al.'s (2017) specimens.

7- Esophagus length: It was exceptionally very small (about 1/6 that in other specimens) or even absent in Ray et al.' (2017) specimens. 

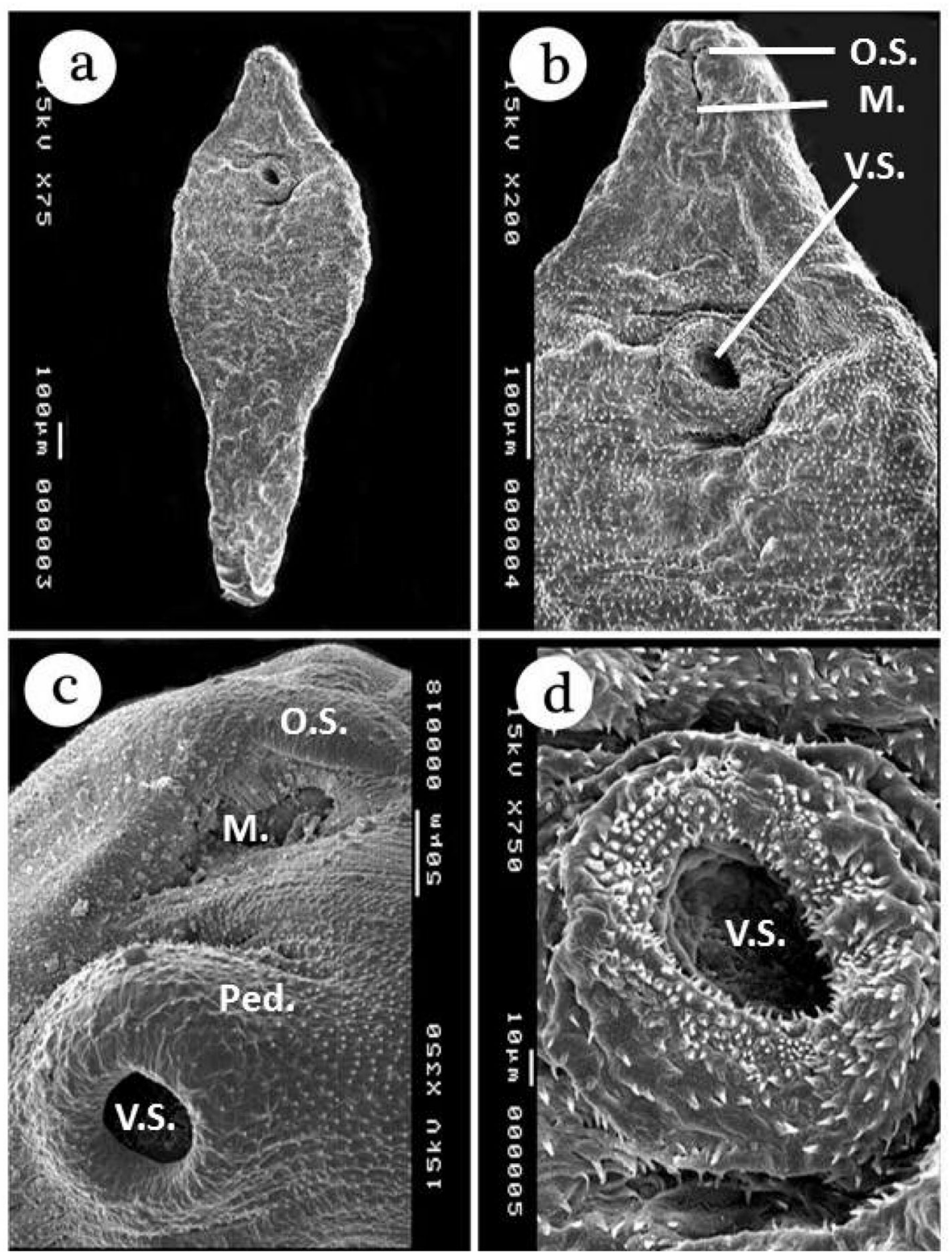

Fig. 4 Scanning electron micrographs of Mesocoelium sociale. a Shows the whole worm. b Shows the anterior end provided with oral sucker (O.S.) surrounding the mouth opening (M.) that appears as a vertical slit, sessile ventral sucker (V.S.), and tegumental spines. c Shows the muscular oral sucker (O.S.) surrounding the mouth opening (M.) that appears as deep hole and ventral sucker on very short peduncle (Ped.). $\mathbf{d}$ Shows magnified ventral sucker (V.S.) surrounded by dense tegumental spines

8- Egg size: Slight acceptable differences in all compared forms while eggs described by Ray et al. (2017) were surprisingly very small in length $(1 / 3 \mathrm{rd}$ to $2 / 3$ rd the length) in all other described forms.

There have been studies suggesting that there are wide ranges of variability in many of the characteristics commonly used to separate mesocoeliid species (Freitas, 1963; Thomas, 1965; Mettricr \& Dunkley, 1968; Goldberg et al., 2005; Goldberg, Bursey, \&
Kraus, 2009) which has been the basis for synonymies within the genus (Dronen et al., 2012).

From the description and figures presented by previously described forms, several remarks were noticed as follows:

1- In Cheng's (1960) form:

a- With only one body form (elongate).

b- Testes at sides of acetabulum overlapping caeca. 

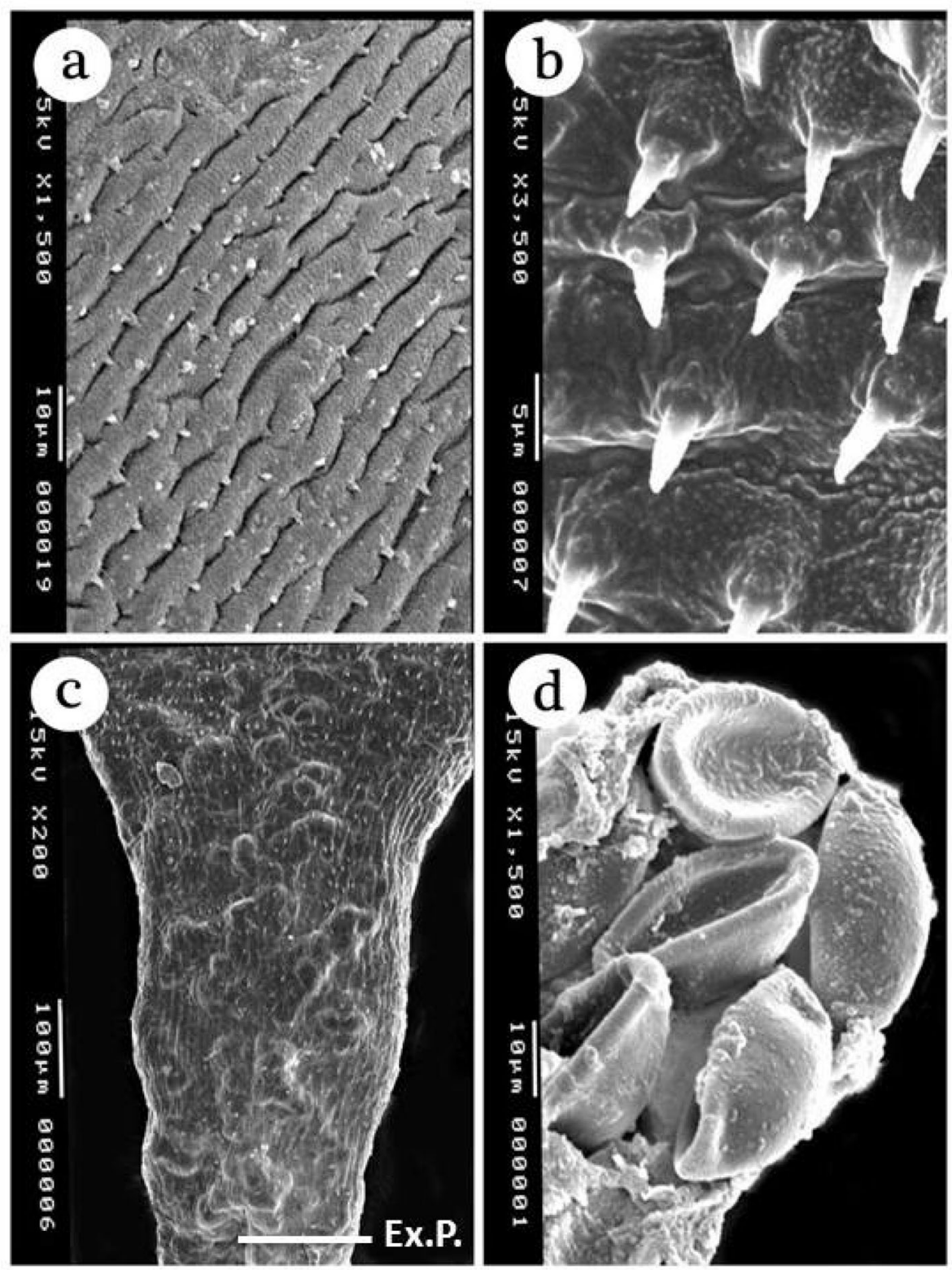

Fig. 5 Scanning electron micrographs of Mesocoelium sociale. a Shows the body surface wrinkles provided with spines. b Shows the tegument provided with curved distal-end spines arranged in transverse rows. c Shows the posterior part of the body with sparse tegumental spines, uterine coils filled with eggs, and terminate with an excretory pore (Ex.P.). d Shows the eggs with thick convex shells

c- Genital pore ventral in the middle of the esophagus. The ovary was posterior to the right testis.

d- Vitellaria of largely separated follicles from lateral margins of the oral sucker to tips of caeca; never intercaecal.

However, in his drawing, the genital pore was a little above intestinal bifurcation and the two testes were obliquely located on both sides of the acetabulum and not on the same level.
2- In Wongsawad et al.'s (1998) form:

a- The body shape was not mentioned; oral sucker bigger than the ventral.

b- Intestinal caeca reaching a posterior third of the body.

c- Testes located obliquely at sides of the ventral sucker, near to caeca, but not overlapping them.

d- Genital pore median at the pharyngeal level. 


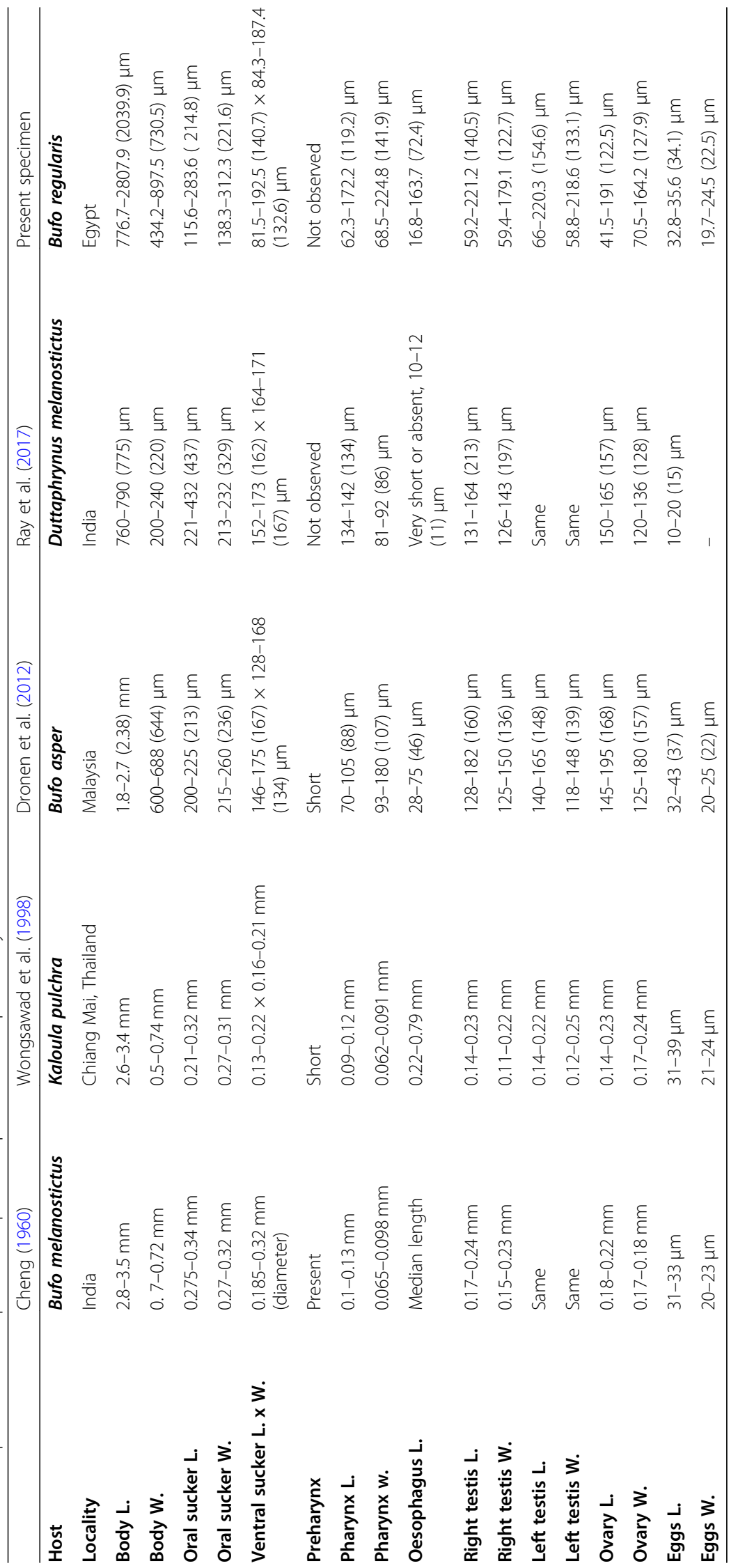


However, in their drawing oral sucker seems to be smaller than ventral sucker, intestinal caeca terminate a little above the anterior half of the body and genital pore located just above the intestinal bifurcation.

3- In Dronen et al.'s (2012) form:

a- Body sociale type, small, elliptical.

b- Esophagus longer than prepharynx. Caeca reach well posterior to the ovary.

c- Testes mostly side by side to slightly diagonal, overlapping ventral sucker.

d- Genital pore at the level of caecal bifurcation, slightly submedian.

e- Ovary immediately posterior to the right testis.

f- Vitelline follicles distributed along caeca from the posterior margin of the pharynx and terminating near to or surpassing caecal ends.

In the present authors' opinion, Dronen et al. (2012) provided the best and most correct description which more or less coincides with the present described Egyptian form. From their drawing, it is clear that the vitelline follicles' termination is not bilaterally similar and maybe a little above the tip of the intestinal caeca.

4- In Ray et al.'s (2017) form:

a- All measurements are markedly smaller than all previously described and the present form.

b- Despite that, measurements of suckers and gonads are noticeably larger than the present samples.

c- Eggs were surprisingly very small (less than $2 / 3$ of the present eggs).

d- Morphological variations were reported (documented by drawings) including intestinal caeca equal or unequal extending to the middle of the body or slightly beyond it, testes rounded or oval, symmetrical, one on each side of the acetabulum, obliquely placed or abnormally developed, genital pore mostly at the level of intestinal bifurcation or pre-bifurcal but maybe post-bifurcal (which deletes the worms from M. sociale), and vitellaria extend from pharyngeal region up to the end of intestinal caeca, mostly non-confluent but sometimes confluent well. All these differences throw a great deal of doubt about the taxonomical identification of Ray et al.'s (2017) form, despite being the most recently redescribed form.

From Egypt, only Mesocoelium monas (Rudolphi, 1819) Freitas, 1958 was identified and redescribed from Bufo regularis by Saad et al. (2000) in Aswan, Upper Egypt. It was reported at a very high rate of infection (83.5\%) out of 850 toads which gave the author a good chance to examine and describe many worms and illustrating some biological variations and deviations from their original description. It seems that these morphological variations are a characteristic feature of the genus as it was noticed in $M$. sociale described in the present samples. Surprisingly, no mesocoeliid parasites were detected in 291 Bufo regularis and 12 Rana sp. examined during a wide-scale work done by Mohamed (1996) in Sohag Governorate which is very near at Assiut Governorate. Recently, the molecular characterization of M. monas was elucidated by Mansour et al. (2014) from specimens collected from Bufo regularis obtained from Dakahliya and Giza Governorates. However, they did not describe the morphological characters of the parasite, stating that these parasites were known to them from many master's and Ph.D. thesis without documenting the references of these works, which throws much doubt on their identification.

\section{Conclusion}

Mesocoelium sociale (Luhe, 1901) Odhner, 1910 is recorded for the first time from Egypt as a trematode parasite of the Egyptian toads Bufo regularis and described by a light microscope. As well, the parasite was compared with previously described forms with the discussion of its taxonomical situation. The scanning electron microscopy of $M$. sociale was not described before; hence, it is described for the first time worldwide with many fine ultrastructure details in the present study. The present authors recommend the ultrastructure of other described mesocoeliid species which may be of great benefit in species separation.

\section{Acknowledgements}

The authors would like to thank the department of Zoology, Assiut University, Egypt, for providing the necessary technical support during the conduct of the present work.

\section{Authors' contributions}

HTh designed the research idea and over-all work and wrote the manuscript. RKh helped in writing the manuscript and revised its scientific and linguistic contents. The authors read and approved the final manuscript.

\section{Funding}

This research did not receive any specific grant from funding agencies in the public, commercial, or not-for-profit sectors.

Availability of data and materials

All the data generated from this study is included in the paper and can be accessed from the corresponding author upon request approval.

\section{Ethics approval and consent to participate}

All applicable institutional, national, and international guidelines for the care and use of animals (Toads) were followed.

Consent for publication

Not applicable

Competing interests

The authors declare that they have no competing interests. 


\section{Author details}

${ }^{1}$ Laboratory of Parasitology, Department of Zoology, Faculty of Science, Assiut University, Assiut 71526, Egypt. ${ }^{2}$ Department of Parasitology, Faculty of Medicine, Assiut University, Assiut 71526, Egypt.

Received: 15 February 2020 Accepted: 15 April 2020

Published online: 12 May 2020

\section{References}

Calhoun, D. M., \& Dronen, N. (2012). A reevaluation of specimens of Mesocoelium monas (Platyhelminthes: Digenea: Mesocoeliidae) from the Natural History Museum, UK and the United States National Parasite Collection, USA. Zootaxa, 3589, 1-29.

Cheng, T. C. (1960). Studies on trematode Family Brachycoeliidae. IV. A revision of the genus Mesocoelium Odhner, 1911; and status of Pintnaria Poche, 1907. The American Midland Naturalist, 63(2), 439-469.

Dronen, N. O., Calhoun, D. M., \& Simcik, S. R. (2012). Mesocoelium Odhner, 1901 (Digenea: Mesocoelidae) revisited; a revision of the family and re-evaluation of species composition in the genus. Zootaxa, 3387, 1-96.

Fiscthal, J. H., \& Kuntz, N. E. (1965). Digenetic trematodes of fishes from North Borneo (Malaysia). Proceedings of the Helminthological. Society of Washington, $32(1), 63-71$.

Freitas, J. F. (1958). Breve nota söbre o Distoma monas Rudolphi, 1819 (Trematoda). Revista Brasiliera de Biologia, 18, 171-174.

Freitas, J. F. (1963). Rivsao da familia Mesocoeliidae Dollfus, 1933 (Trematoda). Memórias do Instituto Oswaldo Cruz, 61, 177-311.

Goldberg, S. R., Bursey, C. R., \& Kraus, F. (2009). Endoparasites of 12 species of Sphenomorphus (Squamata: Scincidae) from Papua New Guinea. Comparative Parasitology, 76, 58-83.

Goldberg, S. R., Bursey, C. R., \& Telford Jr., S. R. (2005). Metazoan parasites of four species of lizards, Gyhera mutilate, Hemidactylus frenatus (Gekkonidae) Mabuya cumingi, Maboya multifasciata (Scincidae), and one species of snake, Rhamphotyphalops braminus (Typhlopidae) from the Philippines Islands. Comparative Parasitology, 72, 88-101.

Gomes, T., Melo, F., Giese, E., Furtado, A., Goncalves, E., \& Santos, J. (2013). A new species of Mesocoelium (Digenea: Mesocoeliidae) found in Rhinella marina (Amphibia: Bufonidae) from Brazilian Amazonia. Memorias do Instito. Oswaldo Cruz, Rio de Janiero, 108 (2), 186-191.

Luhe, M. (1901). Zwei neue Distomen aus indischen Anuren. Centralblatt für Bakteriologie, Parasitenkunde und Infektionsk-rankheiten, 30, 166-177.

Mansour, M. F. A., Ellazek, Y. O., \& Madkour, M. M. (2014). Molecular characterization of five digenetic trematode species from different hosts in Egypt. Egyptian. Journal of Biology. (Zoology.), 10 (1), 1-8.

Mettricr, D. F., \& Dunkley, L. C. (1968). Observations on the occurrence, growth and morphological variations of the trematode Mesocoelium danforthi Hoffman, 1935 in Jamica. Caribbean Journal of Science, 8, 71-94.

Mohamed, A. H. (1996). Studies on endoparasites of some amphibian hosts in Sohag Governorate. M. Sc. Thesis, Zoology (Parasitology), Faculty of Science, Sohag University.

Norval, G., Goldberg, S. R., Bursey, C., MAO, J., \& Slater, K. (2014). Internal parasites of lizards from Taiwn. Herpetological Conservation and Biology, 9(3), 484-494.

Odhner, T. (1910). Nordostafrikanische Trematoden, grösstenteils vom Weissen Nil (von der Schwedischen Zoologischen Expedition gesammelt). Res. Swedish Zool. Exped. Egypt., iv, (23a), 1-166.

Ray, S., Agrawal, N., \& Pandey, K. C. (2017). Validation of digenetic trematodes, using molecular markers, a case study of Indian species of Mesocoelium Odhner, 1911. Asian Journal of Experimental Sciences, 31(1), 15-23.

Rudolphi, C. (1819). Entozsoorm synopsis cui accedunt mantissa duplex et índices locupletissimi. Berolini, 811 pp.

Saad, A. I., Khalifa, R., \& Moustafa, N. (2000). Studies on morphology and taxonomy of Mesocoelium monas (Roudolphi, 1819) Freitas, 1958 a common intestinal fluke of Bufo regularis in Aswan. Journal- Egyptian German Society Zoology., 33(D), 219-234.

Skrjabin, K. I., \& Morozov, F. N. (1959). Family Mesocoeliidae Dollfus, 1950. In Skrjabin, K.I., Trematodes of animals and man. Moskva, 16, 635-703 (In Russian).

Thomas, J. D. (1965). The anatomy, life history and size allometry of Mesocoelium monody Dollfus, 1929. Proceedings of the Zoological Society of London, 146, 413-446.

Wongsawad, C., SEY, O., Rojanapaibul, A., Chariyahpongpun, P., Suwattanacoupt, S., Marayong, T., ... Rojtinnakorn, J. (1998). Trematodes from amphibians and reptiles of Thailand. Journal of the Science Society of Thailand, 24, 265-274.
Yamaguti, S. (1958). The digenetic trematodes of vertebrates. New York, USA: Interscience publisher Inc.

Yamaguti, S. (1971). Synopsis of digenetic trematodes of vertebrates. Vol I, (pp. 147). Tokyo: Keigaku Publishing.

\section{Publisher's Note}

Springer Nature remains neutral with regard to jurisdictional claims in published maps and institutional affiliations.

\section{Submit your manuscript to a SpringerOpen ${ }^{\circ}$ journal and benefit from:}

- Convenient online submission

- Rigorous peer review

- Open access: articles freely available online

- High visibility within the field

- Retaining the copyright to your article

Submit your next manuscript at $\boldsymbol{\nabla}$ springeropen.com 